\title{
A further look at quantitative trait loci affecting growth and fatness in a cross between Meishan and Large White pig populations
}

\author{
Raquel Quintanilla ${ }^{\mathrm{a} * *}$, Denis Milan ${ }^{\mathrm{b}}$, \\ Jean-Pierre BIDANEL ${ }^{\text {a* }}$ \\ a Station de génétique quantitative et appliquée, \\ Institut national de la recherche agronomique, 78352 Jouy-en-Josas Cedex, France \\ ${ }^{b}$ Laboratoire de génétique cellulaire, Institut national de la recherche agronomique, \\ 31326 Castanet Tolosan Cedex, France
}

(Received 23 April 2001; accepted 15 October 2001)

\begin{abstract}
A detailed quantitative trait locus (QTL) analysis of growth and fatness data from a three generation experimental cross between Large White (LW) and Meishan (MS) pig breeds was carried out to search for sex $\times$ QTL interactions, imprinting effects and multiple linked QTLs. A total of $530 F_{2}$ males and $573 F_{2}$ females issued from $6 F_{1}$ boars and $23 F_{1}$ sows were typed for a total of 137 markers covering the entire porcine genome. Nine growth traits and three backfat thickness measurements were analysed. All analyses were performed using line cross regression procedures. A QTL with sex-specific expression was revealed in the proximal region of chromosome 8 , although some confusion between herd and sex effects could not be discarded. This previously undetected QTL affected male growth during the fattening period, with a favourable additive effect of the LW allele. The analyses also revealed the presence of two linked QTLs segregating on chromosome 1, affecting growth traits during the post-weaning period. The first QTL, previously detected using a single QTL model, was located at the end of the $\mathrm{q}$ arm of chromosome 1 and had a favourable MS allele. The second QTL had a favourable LW allele and was located in the proximal extremity of the $\mathrm{q}$ arm of chromosome 1. Suggestive genomic imprinting was found in the distal region of chromosome 9 affecting growth during the fattening period.
\end{abstract}

pig / growth / sex-QTL interaction / imprinting / linked QTLs

\footnotetext{
* Correspondence and reprints

E-mail: bidanel@dga.jouy.inra.fr

** On leave from Departamento de Producción Agraria, Universidad Pública de Navarra, Pamplona, Spain
} 


\section{INTRODUCTION}

Beyond the numerous published genetic maps of the porcine genome, e.g. [4, $12,27,28]$, systematic searches of quantitative trait loci (QTL) in pigs have been performed during the last years $[3,10,17,18,20,23-25,29-34,36]$. These experiments have revealed a number of genome regions affecting quantitative traits of economic importance but, with some exceptions [11,17,18,22], little effort has been invested in searching multiple QTLs in the same linkage group or studying non-Mendelian forms of expression. About this last point, the phenomenon of parent-of-origin specific expression, or genomic imprinting, has been thoroughly studied in humans and mice, and almost 40 imprinted genes have already been described [21]. In livestock, the Callypige locus in sheep has been shown to be imprinted [14], and evidence of genomic imprinting in pigs has been found by several authors [11,17,22]. Evidence of sex-specific QTL expression has been reported for some traits and chromosomal regions [18]. Yet, neither imprinting effects nor the sex $\times$ QTL interaction have been usually studied in QTL analyses.

A considerable experiment has been conducted at INRA to map loci affecting a number of economically important traits in a three generation experimental cross between Large White (LW) and Meishan (MS) pig breeds. Recently, a number of QTLs underlying the genetic differences between these breeds concerning growth and fatness have been mapped from a whole-genome scan [5]. The objective of this paper is to provide a more exhaustive analysis about the form of expression of genome regions contributing to genetic variation of growth and fatness in this $\mathrm{LW} \times \mathrm{MS}$ crossbred population. For this purpose, sex $\times$ QTL interactions as well as the presence of imprinting effects have been explored, and the presence of more than one QTL per chromosome has been tested.

\section{MATERIALS AND METHODS}

\subsection{Experimental population and traits analysed}

The experimental population described in Bidanel et al. [5] was used for this study. It consisted in $1083 \mathrm{~F}_{2}$ animals, derived from a cross between MS and LW outbred populations, distributed in 23 full sib families. To obtain the $F_{2}$ population, six $F_{1}$ litters were produced by mating six unrelated LW boars to six lowly related MS sows. One boar and three or four sows from each litter were kept for breeding, and three to five $F_{1}$ sows were mated to each $F_{1}$ boar in order to produce the $F_{2}$ population. All $F_{2}$ piglets were individually weighed at birth and at three weeks of age. The piglets were weaned at 28 days of age and placed in collective pens until the beginning of the fattening period, at 10 weeks of age. Males and females were fattened in different herds, from 70 
to 150 (females) or 160 (males) days of age. All animals were weighed and measured for backfat thickness at several ages during the testing period.

The traits analysed in this study were live weights $(\mathrm{kg})$ at birth $(\mathrm{BW})$ and at 3 , 10, 13, 17 and 22 weeks of age (W3, W10, W13, W17 and W22, respectively); average backfat thickness (mm) at 13, 17 and 22 weeks of age (ABT13, ABT17 and ABT22, respectively); average daily gain $\left(\mathrm{g} \cdot \mathrm{d}^{-1}\right)$ from birth to 3 weeks of age (ADG1), from 3 to 10 weeks of age (ADG2) and during the fattening period (ADG3).

More information about the sibship structure, management and data recording of the $\mathrm{F}_{2}$ experimental population, along with overall means and standard deviations of the traits analysed, can be found in [5].

\subsection{Genotyping and map construction}

The almost $1100 \mathrm{~F}_{2}$ animals, their 29 parents and 12 grandparents were genotyped for 136 microsatellite markers and for the major histocompatibility complex (SLA). The panel of markers covered all 18 autosomes and the $\mathrm{X}$ chromosome. The number of markers per Sus Scrofa chromosome (SSC) varied between 3 (SSC 18) and 12 (SSC 7). Multipoint linkage analyses were carried out for males, females and both sexes with version 2.4 of the CriMap software [15]. Recombination units were then transformed to map distances using the Haldane mapping function. The final sex-average map covered by the marker panel spanned $2477 \mathrm{cM}$ for the 18 autosomes. More details about the panel of markers and the genotyping methodology are given in [5].

\subsection{Statistical methods}

All analyses were performed using the regression approach developed by Haley et al. [16] for the analysis of three generation pedigrees derived from a cross between outbred lines. This approach assumes that the founder populations are fixed for alternative QTL alleles, i.e. only two alleles are segregating in the $F_{2}$ population. These two alleles will be denoted $\mathrm{Q}$ for the MS allele and $\mathrm{q}$ for the LW allele. Under this assumption, the probability of an $F_{2}$ individual being one of four possible QTL genotypes [p(QQ), $p(Q q)$, $\mathrm{p}(\mathrm{qQ})$ or $\mathrm{p}(\mathrm{qq})$ ], conditional on the marker genotypes, were computed as described by Haley et al. [16] at any putative location in the genome. These probabilities were then used in a least squares framework to investigate the genetic model underlying the trait of interest. Most of the analyses were performed by means of the software developed by Seaton $e t$ al., available at http://latte.cap.ed.ac.uk/H+K_v2/hkcServlet.html. Sex average distances were used in all analyses, since Knott et al. [18] showed that using sex-specific maps had limited effects on the results. The different hypotheses (sex $\times$ QTL interaction, linked QTLs, genomic imprinting and family $\times$ QTL interaction) 
were tested by computing, at every $\mathrm{cM}$ of the whole genome, the reduction in sum of squares (F-ratio test) caused by adding the new component/s to a no-QTL and to a single QTL models, as described below.

\subsubsection{Models of analysis}

\section{Single QTL model}

A single QTL regression model, required to contrast the different hypotheses analysed, was first used, i.e.:

$$
y_{i j k}=\mu+s_{j}+g_{k}+\beta \operatorname{cov}_{i}+c_{\mathrm{a} i} a+c_{\mathrm{d} i} d+e_{i j k}
$$

where:

$y_{i j k}$ is the phenotype of the $i$ th $\mathrm{F}_{2}$ offspring;

$\mu$ is the overall mean;

$s_{j} \quad$ is a fixed sex effect;

$g_{k}$ is a fixed contemporary group effect; two different grouping strategies were used for all analyses: (1) animals from the same fattening batch were considered as contemporary; (2) each litter was considered as a different contemporary group. Results regarding the hypotheses tested did not differ substantially, so that only results from the analyses with fattening batch as a fixed effect are presented;

$\operatorname{cov}_{i}$ is a covariate that varied according to the trait analysed: age at measurement for weights and ABT during the fattening period, and litter size for pre-weaning traits. Fatness traits adjusted for live weight were not analysed as previous analyses [5] had shown that adjusting ABT measurements for either age or weight gives similar results;

$\beta \quad$ is the regression coefficient on the covariate;

$a, d$ are, respectively, the additive and dominance effects of a putative QTL as described by Falconer and Mackay [13], i.e. $a$ is the effect of the genotype QQ on the trait (the effect of genotype qq will be $-a$ ) and $d$ is the effect of genotypes Qq and qQ on the trait;

$c_{\mathrm{a} i}$ is the coefficient of the $i$ th individual for the additive component at any putative location in the genome, which is equal to $\mathrm{p}(\mathrm{QQ})-\mathrm{p}(\mathrm{qq})$;

$c_{\mathrm{d} i}$ is the coefficient of the $i$ th individual for the dominance component at any putative location in the genome, which is equal to $\mathrm{p}(\mathrm{Qq})+\mathrm{p}(\mathrm{qQ})$;

$e_{i j k}$ is the residual error. 


\section{Sex $\times$ QTL interaction}

In order to test whether QTL effects ( $a$ and $d$ ) differed in males and females, sex $\times$ QTL interactions were added to model 1 as follows:

$$
y_{i j k}=\mu+s_{j}+g_{k}+\beta \operatorname{cov}_{i}+c_{\mathrm{ai} i}\left(a s_{j}\right)+c_{\mathrm{di}}\left(d s_{j}\right)+e_{i j k}
$$

where $y_{i j k}, \mu, s_{j}, g_{k}, \beta, \operatorname{cov}_{i}, c_{\mathrm{ai}}, c_{\mathrm{d} i}$ and $e_{i j k}$ have the same meaning as in model $1, a s_{j}$ and $d s_{j}$ are, respectively, additive and dominance effects for the sex $j$. Two different F-statistics where computed to test this interaction. The first one was obtained by comparing model 2 with a model without QTL $\left(\mathrm{F}_{4 \mathrm{df}}\right.$, an F-value with 4 degrees of freedom in the numerator). When $\mathrm{F}_{4 \mathrm{df}}$ reached significance, a second test was performed comparing model 2 with the best single QTL model ( $\mathrm{F}_{2 \mathrm{df}}$, with 2 degrees of freedom in the numerator). The interaction was considered as significant only if both statistics reached at least a suggestive level of significance.

\section{Two QTL analyses}

The presence of two QTLs in the same linkage group was tested by adding additive and dominance effects for a second QTL in the model, i.e.:

$$
y_{i j k}=\mu+s_{j}+g_{k}+\beta \operatorname{cov}_{i}+c_{\mathrm{a} i 1} a_{1}+c_{\mathrm{di} 1} d_{1}+c_{\mathrm{ai} 2} a_{2}+c_{\mathrm{d} i 2} d_{2}+e_{i j k}
$$

where $y_{i j k}, \mu, s_{j}, g_{k}, \beta, \operatorname{cov}_{i}$ and $e_{i j k}$ have the same meaning as in model 1, $a_{1}$, $a_{2}, d_{1}, d_{2}$ are, respectively, additive and dominance effects for QTL 1 and 2, and $c_{\mathrm{a} i 1}, c_{\mathrm{a} i 2}, c_{\mathrm{d} i 1}, c_{\mathrm{d} i 2}$ are the corresponding coefficients. A two-dimensional search was carried out by fitting model 3 to all possible combinations of two positions on the chromosome. Two F-statistics were computed. The first F-value was obtained by contrasting model 3 with a no QTL model $\left(\mathrm{F}_{4 \mathrm{df}}\right)$. When $\mathrm{F}_{4 \mathrm{df}}$ reached the suggestive threshold, a second $\mathrm{F}$-value was calculated by contrasting model 3 with the best single QTL model $\left(\mathrm{F}_{2 \mathrm{df}}\right)$. The presence of two QTLs on the linkage group was concluded only when both F-statistics reached a suggestive level of significance.

\section{Imprinting}

The presence of imprinting effects $(i)$ was tested by considering the paternal or maternal origin of grandparental (MS or LW) alleles, including the difference between the two classes of heterozygotes in the model as suggested by Knott et al. [18], i.e. :

$$
y_{i j k}=\mu+s_{j}+g_{k}+\beta \operatorname{cov}_{i}+c_{\mathrm{ai}} a+c_{\mathrm{di}} d+c_{i i} i+e_{i j k} \quad\{\text { model 4\} }
$$


where $y_{i j k}, \mu, s_{j}, g_{k}, \beta, \operatorname{cov}_{i}, a, d, c_{\mathrm{a} i}, c_{\mathrm{d} i}$ and $e_{i j k}$ have the same meaning as in model $1, i$ is the imprinting effect, and $c_{i i}=\mathrm{p}(\mathrm{Qq})-\mathrm{p}(\mathrm{qQ})$ is the corresponding coefficient. Model 3 was first contrasted with a no QTL model $\left(\mathrm{F}_{3 \mathrm{df}}\right.$, with 3 degrees of freedom in the numerator). When significant, model 3 was compared with the best single QTL model to test the significance of the imprinting effects ( $\mathrm{F}_{1 \mathrm{df}}$, with 1 degree of freedom in the numerator).

\section{Family $\times$ QTL interaction}

A model with a full-sib family fixed effect and a family $\times$ QTL interaction was also run to test the differences in QTL effects between full-sib families, which would suggest different alleles segregating in founder populations. This interaction between full-sib family and QTL effects never reached significance for any trait at any position on the whole genome.

\subsubsection{Significance thresholds}

Significance thresholds were determined empirically by data permutation as described by Churchill and Doerge [8]. For each permutation, a wholegenome analysis was performed in order to locate the highest F-value. A total of 10000 permutations was carried out to obtain the $\mathrm{F}$ distribution under the null hypothesis (no linked QTL) for three traits, ABT17, W17 and ADG3. The 5\% chromosome-wide significance levels obtained (respectively, 5.9, 5.3 and 5.7) did not differ much between traits and were rather similar to threshold values reported by other authors $[18,25]$. Finally, it was decided to use the most conservative value (i.e. 5.9 for $p<0.05$ ) as suggestive $\mathrm{F}_{2 \mathrm{df}}$ threshold for all traits.

Genome-wide significance thresholds were obtained from Bonferroni correction as described by Knott et al. [18]. Considering that 19 independent chromosomes were analysed, the chromosome-wide significance level corresponding to a 0.05 genome-wide significance level was equal to 0.0027 . A conservative $\mathrm{F}_{2 \mathrm{df}}$ genome-wide threshold of 9.0 was considered for all traits.

Models with sex-QTL interaction (model 2), with two QTLs (model 3) and with imprinting (model 4) were tested using approximate significance thresholds obtained as described by Knott et al. [18]: the threshold F ratio obtained from the null hypothesis simulations was converted into a probability of the $\mathrm{F}$ ratio under a standard $\mathrm{F}$ distribution with two degrees of freedom in the numerator. Subsequently, the $\mathrm{F}$ ratio that would give this probability under an $\mathrm{F}$ with one, three or four degrees of freedom in the numerator were also obtained from the standard F distribution. The genome-wide suggestive and significant thresholds obtained using this approximate method were, respectively, 8.0, 4.7, 4.1 and 13.5, 6.1 and 5.5 for $\mathrm{F}_{1 \mathrm{df}}, \mathrm{F}_{3 \mathrm{df}}$ and $\mathrm{F}_{4 \mathrm{df}}$. 


\section{RESULTS}

\subsection{Sex $\times$ QTL interactions}

As shown in Table I, six trait $\times$ chromosome combinations located on three chromosomes (SSC 8, 9 and 10) reached the suggestive threshold for sex $\times$ QTL interaction. Nevertheless, the only genome-wide significant results were obtained for growth traits during the fattening period (W13, W17, W22 and ADG3) on SSC 8. Figure 1 shows the profile of the F-ratio throughout SSC 8 with models 1 (no sex $\times$ QTL interaction) and 2 (sex $\times$ QTL interaction) for these growth traits. F-ratios reached genome-wide significance for all traits with model 2 , whereas only suggestive or non-significant thresholds were obtained with model 1 . The improvement of fit due to the interaction term was significant at the chromosome-wide level (Tab. I). The interaction term had a very limited effect on the most probable position of the QTL, which was located between SW905 and SWR1101, but QTL effects widely differed between sexes. Additive and dominance effects were both non-significant in females. Conversely, the QTL had a highly significant additive effect in males, with a favourable effect of the LW allele. It explained 6.1, 5.1, 12.5 and $7.7 \%$ of the phenotypic variance of W13, W17, W22 and ADG3, respectively. Dominance effects tended to be favourable, but were only significant for W22. The SSC 9 and SSC 10 regions showing suggestive QTL interacting with sex were not detected using model 1 . The sex $\times$ QTL interaction on SSC 10 was also due to differences in additive effects on ABT17, with no effect in males and a favourable effect of the LW allele in females. Conversely, the interaction affecting W10 on SSC 9 was mainly due to a large difference in dominance effects between males and females, with no dominance in males and overdominance in females (Tab. I).

\subsection{Two QTL analyses}

Significant results from the two QTLs genome scans are shown in Table II. Three chromosomal regions reached genome-wide significance for the test of two vs. no QTL ( $\mathrm{F}_{4 \mathrm{df}}-\mathrm{Tab}$. II). As shown by $\mathrm{F}_{2 \mathrm{df}}$ values (Tab. II), the improvement of fit obtained by adding a second QTL was in all cases significant considering the suggestive levels obtained by the permutation test. These significant results all concerned growth traits, as no evidence of linked QTLs was obtained for backfat thickness.

The strongest evidence of linked QTLs was obtained for SSC 1, with four growth traits reaching suggestive significance as compared to the best single QTL model. As shown in Figure 2, the profile of the F-ratio for W10, W13, W17 and ADG2 when a single QTL is fitted already suggested the existence of two equally probable locations. Moreover, these positions were almost the 
Table I. Results from fitting a sex $\times$ QTL interaction.

\begin{tabular}{|c|c|c|c|c|c|c|c|c|}
\hline Trait ${ }^{\text {(a) }}$ & SSC & $\mathrm{F}_{4 \mathrm{df}}{ }^{(\mathrm{b})}$ & $\mathrm{F}_{2 \mathrm{df}}(\mathrm{c})$ & Location & $\mathrm{a}_{\text {female }}{ }^{(\mathrm{d})}$ (s.e.) & $a_{\text {male }}{ }^{(d)}$ (s.e.) & $\mathrm{d}_{\text {female }}{ }^{(\mathrm{d})}$ (s.e.) & $\mathrm{d}_{\text {male }}{ }^{(\mathrm{d})}$ (s.e.) \\
\hline $\mathrm{W} 13(\mathrm{~kg})$ & 8 & $6.12 *$ & $7.15^{+}$ & 27 & $-0.05(0.38)$ & $-1.72(0.38)$ & $-0.85(0.59)$ & $0.97(0.60)$ \\
\hline W17 (kg) & 8 & $6.17^{*}$ & $7.07^{+}$ & 27 & $-0.21(0.57)$ & $-2.45(0.58)$ & $-1.77(0.89)$ & $1.60(0.91)$ \\
\hline W22 (kg) & 8 & $9.15^{* * *}$ & $9.38^{++}$ & 27 & $-0.24(0.82)$ & $-4.71(0.83)$ & $-1.30(1.28)$ & $2.66(1.31)$ \\
\hline $\operatorname{ADG} 3\left(g \cdot d^{-1}\right)$ & 8 & $7.36^{* *}$ & $7.59^{+}$ & 28 & $-1(8)$ & $-43(8)$ & $-7(13)$ & $24(13)$ \\
\hline W10 (kg) & 9 & $5.26^{+}$ & $6.27^{+}$ & 87 & $0.27(0.32)$ & $-0.41(0.32)$ & $1.92(0.54)$ & $-0.40(0.57)$ \\
\hline ABT17 (mm) & 10 & $5.69^{+}$ & $6.72^{+}$ & 27 & $0.95(0.21)$ & $-0.16(0.20)$ & $-0.03(0.30)$ & $-0.20(0.31)$ \\
\hline
\end{tabular}

(a) See text for the definition of the traits.

(b) Model $2 v s$. Model without QTL; ${ }^{*} p<0.05,{ }^{* *} p<0.01,{ }^{* * *} p<0.001$ at genome-wide level; ${ }^{+}$suggestive level.

(c) Model $2 v s$. Model 1 with best QTL; ${ }^{+} p<0.05,{ }^{++} p<0.01$ at chromosome-wide level.

(d) Estimates of additive (a) and dominance (d) effects in females and males; s.e. standard error. 
Table II. Results from fitting two QTLs.

\begin{tabular}{|c|c|c|c|c|c|c|c|c|c|}
\hline \multirow[b]{2}{*}{ Trait $^{(a)}$} & \multirow[b]{2}{*}{$\mathrm{SSC}$} & \multirow[b]{2}{*}{$\mathrm{F}_{4 \mathrm{df}}(\mathrm{b})$} & \multirow[b]{2}{*}{$\mathrm{F}_{2 \mathrm{df}}{ }^{(\mathrm{c})}$} & \multicolumn{2}{|c|}{ Location $^{(\mathrm{d})}$} & \multicolumn{4}{|c|}{ Estimates ${ }^{(\mathrm{e})}$} \\
\hline & & & & $\mathrm{L}_{\mathrm{QTL} 1}$ & $\mathrm{~L}_{\mathrm{QTL} 2}$ & $\mathrm{a}_{\mathrm{QTL} 1}$ (s.e.) & $\mathrm{a}_{\mathrm{QTL} 2}$ (s.e.) & $\mathrm{d}_{\mathrm{QTL} 1}$ (s.e.) & $\mathrm{d}_{\mathrm{QTL} 2}$ (s.e.) \\
\hline $\operatorname{ADG} 2\left(g \cdot d^{-1}\right)$ & 1 & $7.79^{* *}$ & $7.65^{+}$ & 81 & 175 & $-12(3)$ & $12(3)$ & $4(5)$ & $-5(4)$ \\
\hline W10 (kg) & 1 & $8.14^{* *}$ & $9.01^{++}$ & 85 & 167 & $-0.97(0.22)$ & $0.93(0.22)$ & $0.16(0.35)$ & $-0.25(0.35)$ \\
\hline W13 (kg) & 1 & $11.10^{* * *}$ & $8.85^{++}$ & 109 & 173 & $-1.04(0.24)$ & $1.36(0.25)$ & $-0.13(0.34)$ & $-0.62(0.36)$ \\
\hline W17 (kg) & 1 & $7.30^{*}$ & $7.05^{+}$ & 110 & 175 & $-1.36(0.36)$ & $1.54(0.36)$ & $0.07(0.50)$ & $-0.66(0.51)$ \\
\hline WB (kg) & 3 & $6.28^{*}$ & $7.77^{+}$ & 23 & 29 & $-0.08(0.09)$ & $0.05(0.08)$ & $-0.39(0.10)$ & $0.36(0.08)$ \\
\hline $\operatorname{ADG} 2\left(g \cdot d^{-1}\right)$ & 7 & $10.39^{* * *}$ & $6.97^{+}$ & 70 & 113 & $17(3)$ & $-9(3)$ & $12(4)$ & $13(5)$ \\
\hline
\end{tabular}

(a) See text for the definition of the traits.

(b) Model 3 vs. Model without QTL; ${ }^{*} p<0.05,{ }^{* *} p<0.01,{ }^{* * *} p<0.001$ at genome-wide level.

(c) Model 3 vs. Model $\{1\}$ with best single QTL; ${ }^{+} p<0.05,{ }^{++} p<0.01$ at chromosome-wide level.

(d) Most likely position of QTL1 and QTL2, respectively.

(e) Estimates of additive (a) and dominance (d) effects of QTL1 and QTL2; s.e. standard error. 


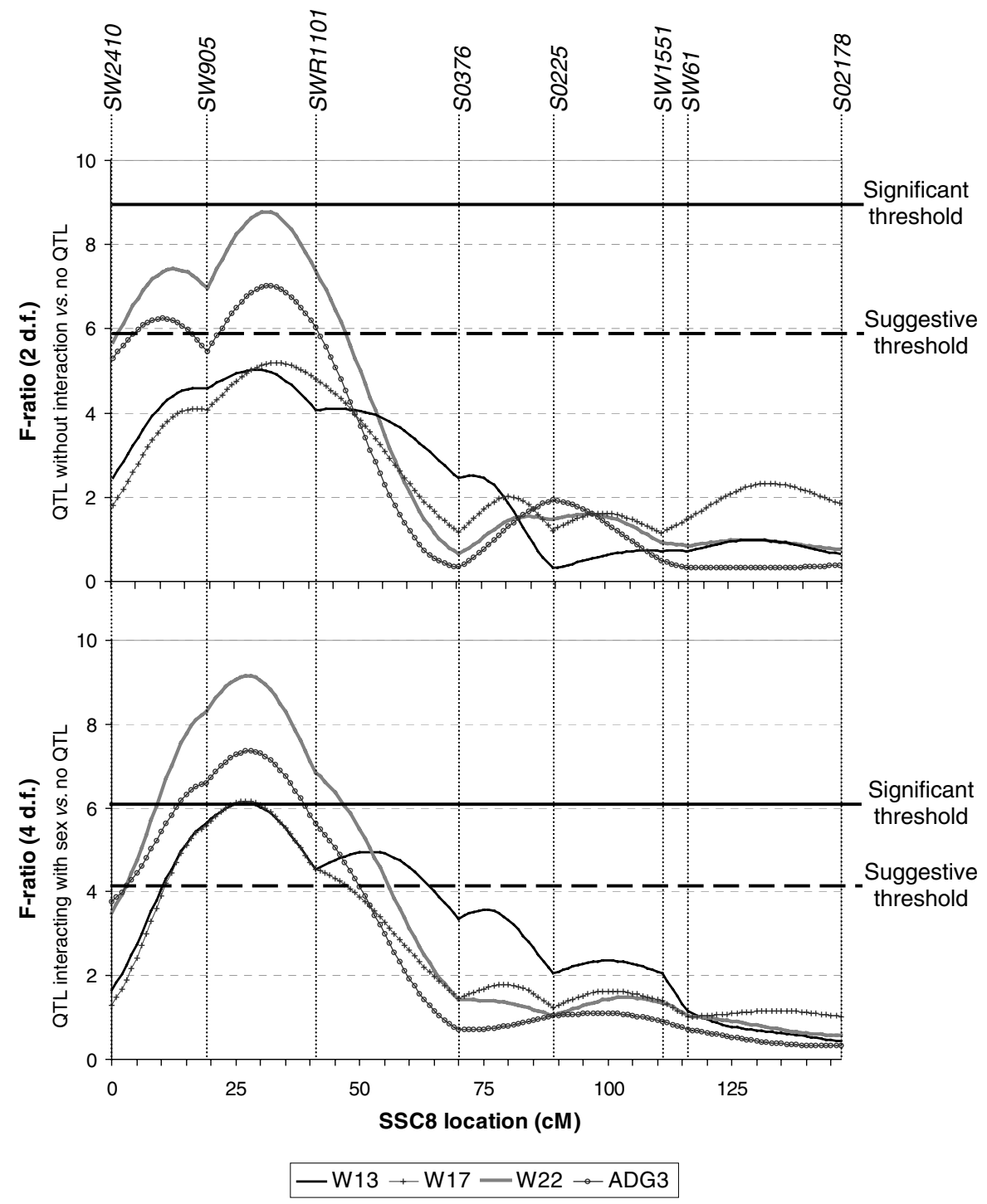

Figure 1. Profile of F-ratios throughout the SSC 8 for growth traits with significant sex-QTL interaction, by fitting two models: a single QTL model (without interaction) and a model including the sex-QTL interaction. W13, W17 and W22, live weights $(\mathrm{kg})$ at 13,17 and 22 weeks of age, respectively; ADG3, average daily gain $\left(\mathrm{g} \cdot \mathrm{d}^{-1}\right)$ during the fattening period.

same as the most likely obtained positions for the two linked QTLs with a two-loci model (Tab. II): one QTL at the end of the $\mathrm{q}$ arm and the second one near S0396 for pre-fattening traits (W10 and ADG2), and near S0155 for 


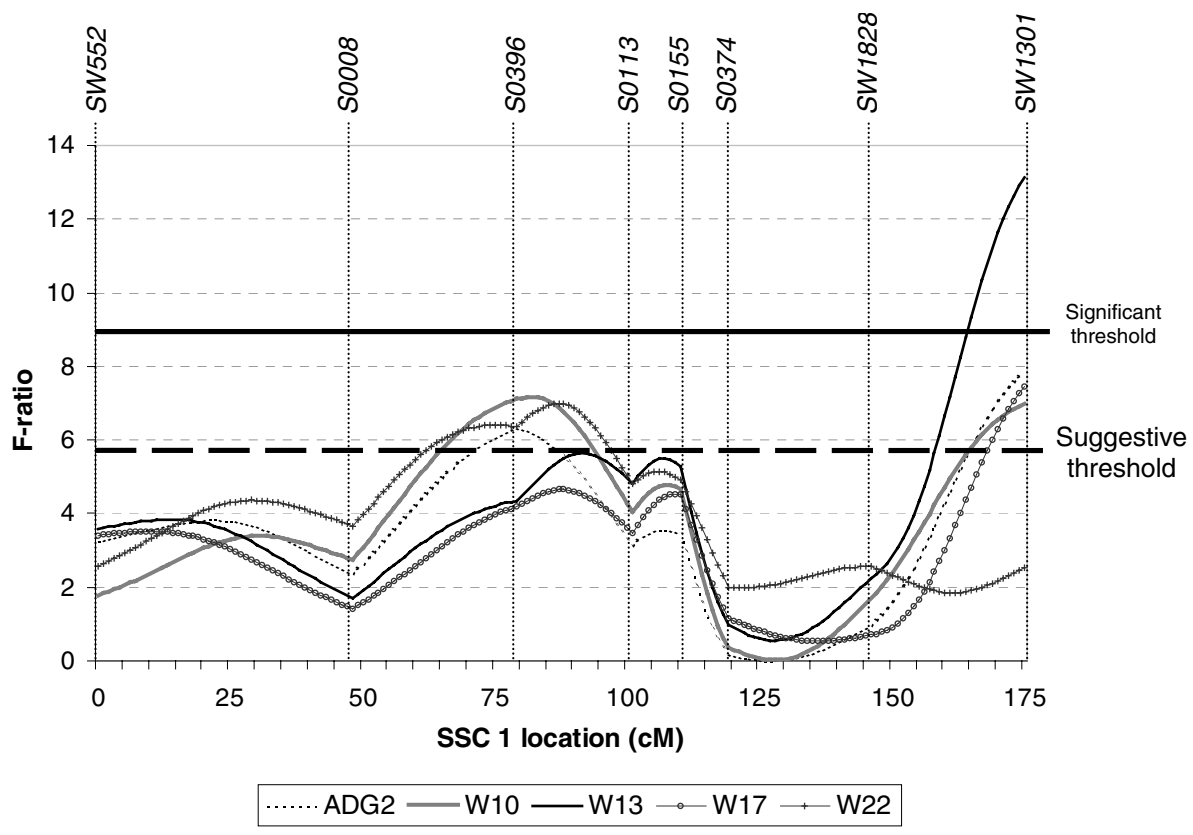

Figure 2. Profile of F-ratios throughout SSC 1 for post-weaning growth traits when a single QTL is fitted (model with QTL vs. no QTL model). ADG2, average daily gain $\left(\mathrm{g} \cdot \mathrm{d}^{-1}\right)$ from 3 to 10 weeks of age; W10, W13, W17 and W22, live weights $(\mathrm{kg})$ at $10,13,17$ and 22 weeks of age, respectively.

later weights (W13 and W17). Additive effects of the two QTLs were of the same magnitude, but with opposite signs. The QTL located at the end of the $\mathrm{q}$ arm showed a positive effect of the MS allele, whereas the LW allele had a favourable effect at the second QTL. Dominance effects were always non-significant.

A better fit was also obtained with a two-QTLs model as compared to a single QTL model for ADG2 on SSC 7. The first QTL had the same most likely position as that previously detected (SLA-S0102 interval), but a larger favourable additive effect of the MS allele. The second QTL was located between SW352 and SW632 markers and had a favourable LW allele. Significantly positive dominance effects were obtained for both QTLs, i.e. MS allele dominance for the first QTL and LW allele dominance for the second one. The average performance of heterozygotes exceeded homozygote average by $3.2-3.4 \%$. The third significant result was for birth weight on chromosome 3 . However, the most likely positions of the two QTLs were very close (23 and $29 \mathrm{cM}$ ). Moreover, only dominance effects were significant, with opposite signs at each location. 
Table III. Results from fitting a model with imprinting.

\begin{tabular}{lccccccc}
\hline Trait $^{(\mathrm{a})}$ & SSC Location & $\mathrm{F}_{3 \mathrm{df}}{ }^{(\mathrm{b})}$ & $\mathrm{F}_{1 \mathrm{df}}{ }^{(\mathrm{c})}$ & $\mathrm{i}^{(\mathrm{d})}($ s.e. $)$ & $\mathrm{a}^{(\mathrm{d})}($ s.e. $)$ & $\mathrm{d}^{(\mathrm{d})}($ s.e. $)$ \\
\hline W22 (kg) & 9 & 122 & $4.73^{+}$ & $9.46^{+}$ & $1.99(0.65)$ & $-0.52(0.60)$ & $1.99(1.01)$ \\
ADG3 (kg) & 9 & 121 & $4.65^{+}$ & $8.29^{+}$ & $19(6)$ & $-5(6)$ & $21(10)$ \\
W17 $(\mathrm{kg})$ & 9 & 122 & $4.71^{+}$ & $6.91 \mathrm{~ns}$ & $1.56(0.45)$ & $-0.25(0.41)$ & $0.84(0.70)$ \\
\hline
\end{tabular}

(a) See text for the definition of the traits.

(b) Model 4 vs. Model without QTL; ${ }^{+}$suggestive level.

(c) Model 4 vs. Model 1 with best single QTL; ${ }^{+} p<0.05$ at chromosome-wide level.

(c) i, a, d, estimates of imprinting, additive and dominance effects, respectively; s.e., standard error.

\subsection{Imprinting}

The results from the whole-genome scan with imprinting effects are shown in Table III. No genome-wide significant imprinted QTL was evidenced, but suggestive results were obtained for W22 and ADG3 on the distal region of SSC 9, between S0384 and SW174 markers. Estimated imprinting effects indicated that heterozygous individuals that had received the MS allele (Q) from the male parent had a higher weight $(+1.98 \pm 0.65 \mathrm{~kg})$ and a larger growth rate $\left(+19 \pm 7 \mathrm{~g} \cdot \mathrm{d}^{-1}\right)$ than heterozygous individuals who had received it from the female parent. Both additive and dominance effects were nonsignificant, which is consistent with the fact that no QTL had previously been detected on SSC 9 [5]. A similar tendency was observed for W17, but the test of the model with imprinting vs. the best model without imprinting $\left(\mathrm{F}_{1 \mathrm{df}}\right.$ - Tab. III) did not reach significance. No other evidence of imprinting effects across the Sus Scrofa genome was found in these analyses.

\section{DISCUSSION}

\subsection{Methodology}

As pointed out by Knott et al. [18] and de Koning et al. [11], the line-cross regression procedure described by Haley et al. [16] can be easily extended to search for non-Mendelian forms of expression and for the presence of multiple linked QTLs. This line-cross model is based on the assumption that different QTL alleles are fixed in founder populations. It is a very powerful model when this corresponds to the true state of nature, and it is rather robust to limited departures from this ideal situation [1]. The absence of significant family $\times$ QTL interaction in the $F_{2}$ population analysed tends to indicate that there are no significant differences in the estimated effects for LW and MS alleles passed through different $F_{1}$ individuals. This result is consistent with those 
of Bidanel et al. [5], who obtained similar results using this line-cross and a half-full sib model, which did not make any assumption about the number and the frequency of QTL alleles in founder populations. It suggests that QTL alleles are likely to be fixed in parental populations, and supports the adequacy of this regression approach for the analysis of such line-cross data. However, it should be kept in mind that the experiment might somewhat lack power to test such an interaction, so the presence of several alleles segregating in the parental populations cannot be totally discarded.

\subsection{Sex $x$ QTL interactions}

The results obtained in these analyses showed the existence of a QTL in the proximal region of SSC 8 associated with live weight and growth rate during the fattening period, but with a sex-specific expression. It exclusively affected growth traits in males, with a purely additive favourable effect of the LW allele. However, it should be kept in mind that males and females were fattened in different fattening units. As a consequence, the observed interaction cannot be unambiguously considered as a sex $\times$ QTL interaction, since it may also reflect the existence of a herd $\times$ QTL interaction. Sex $\times$ QTL interactions have seldom been tested in the analysis of QTL experiments. Yet, Knott et al. [18] also reported a significant sex $\times$ QTL interaction on SSC 8 for the length of the small intestine in a Large White $\times$ Wild Boar cross, with a much larger effect in males than in females. It has to be noted that the model with no interaction only gave suggestive evidence of a QTL [18]. Similarly, no significant (W13 and W17) or suggestive (W22) QTLs were obtained by Bidanel et al. [5] in a first analysis of current data using a model without interaction. It may thus be reasonably hypothesised that some undetected or suggestive QTLs would have been significant if sex $\times$ QTL interaction had been fitted in the model. This is for instance the case for suggestive growth QTLs found on SSC 8 by Casas-Carrillo et al. [7] and Paszek et al. [24] using a no interaction model.

\subsection{Two QTL analyses}

Two-QTLs analyses suggested the existence of linked growth QTLs on SSC 1. The QTL located at the end of the q arm of SSC 1 (QTL2) had already been detected using a single QTL model by Bidanel et al. [5]. The most likely position and estimates of dominance effects were similar in both cases, whereas estimates of additive effects were somewhat lower with the single QTL model. This difference may be due to the additive effects at the second QTL (QTL1), which are in the opposite direction and tend to bias downward the estimates from single QTL models. As emphasised by Knott et al. [18], this may in some instances be due to the fact that separating two closely linked QTLs that are highly confounded is difficult and may give unreliable estimates. This latter 
explanation is rather unlikely for SSC 1, since QTL1 is located at more than $60 \mathrm{cM}$ from QTL2, whose results are very consistent with single QTL analyses. Moreover, a suggestive QTL with the same characteristics as QTL1 (similar position, purely additive favourable LW allele) was also detected in single QTL analyses by Bidanel et al. [5].

Similarly, the two-QTLs model gave rather consistent results for ADG2 on SSC 7. The QTL located in the SLA-SO102 interval had already been revealed at the same position using a single QTL model [5], with a lower estimate of additive effects $\left(10 \pm 2 \mathrm{~g} \cdot \mathrm{d}^{-1} v s .16 \pm 3 \mathrm{~g} \cdot \mathrm{d}^{-1}\right)$ and a slightly larger estimate of dominance effects $\left(16 \pm 4 \mathrm{~g} \cdot \mathrm{d}^{-1} v s .12 \pm 4 \mathrm{~g} \cdot \mathrm{d}^{-1}\right)$ than in the current analysis. Conversely, the two-QTLs result on SSC 3 is more questionable given the very close location of the two QTLs.

Reports of linked QTLs are very scarce in pigs. To our knowledge, the only available results are those of Knott $e t$ al. [18], who reported suggestive evidence of linked QTLs affecting growth rate, abdominal fat and small intestine length in Wild Boar $\times$ Large White crosses. Linked growth QTLs were located on a different chromosome, i.e. SSC 5, than those detected in the current study.

\subsection{Imprinting}

A single chromosomal region on SSC 9 showed suggestive evidence for parent-of-origin specific expression for ADG3 and W22 when running a genome scan using a model with a so-called "imprinting" effect. No imprinted QTL had been previously reported in this chromosomal region in pigs. Yet, several imprinted genes related with early growth and development $[6,26,35,37]$ have been reported in the orthologous region of the human genome (7q11-q22; see comparative mapping at http://www.toulouse.inra.fr/lgc/pig/compare). This unique evidence of imprinting contrasts with the numerous reports of imprinting effects in pigs recently published. Knott et al. [18] reported an improvement of fit for abdominal fat on SSC 4 when including an imprinting effect in the model. Jeon et al. [17] and Nezer et al. [22] showed evidence of an imprinted QTL linked to IGF2 locus (at the distal tip of SSC 2p) in, respectively, Large White $\times$ Wild Boar and Large White $\times$ Pietrain crosses. More recently, de Koning et al. [11] detected four imprinted QTLs in Meishan $\times$ White crosses. These QTLs were located on SSC 2 (affecting backfat thickness) on SSC 6 (2 QTLs affecting intramuscular fat content) and on SSC 7 (affecting muscle depth). The lack of parent-of-origin specific expression in the present study as compared to the study of de Koning et al. [11] may look surprising, since Meishan animals used in both experiments were derived from the same base population. Yet, it may result from allele differences in the "White" population used: only French Large White were used in the French experiment, whereas both Large White and Landrace genes were involved in the Dutch White population. Other hypotheses, such as a sex difference in marker informativity or the existence 
of two or several alleles segregating in parental populations, combined with extreme QTL allele frequency differences between males and females, might also lead to false positive results for imprinting in [11]. However, the lack of significant family $\times$ QTL interaction in the current study tends to indicate that the QTLs are fixed for different alleles in parental populations and that this latter hypothesis is rather unlikely. Finally, the diverging conclusions regarding imprinting may also result from differences in experimental power and particularly statistical methods used. In the study of de Koning et al. [11] paternal and maternal imprinting effects were tested separately against a no-QTL model, and imprinting was considered as present when a single test reached significance. With such as procedure imprinting is not tested as a deviation from a Mendelian inheritance model [19], which may lead to false imprinting results.

\section{CONCLUSIONS}

The objective of this study was to analyse in more detail the genetic architecture of growth and fatness traits in pigs. The presence of sex $\times$ QTL interactions, of linked QTLs, along with suggestive evidence of genomic imprinting, have been revealed. These results tend to indicate that using a single QTL model may not be adequate in all situations, and that departures from the single QTL model usually assumed may be worth being investigated. Yet, further studies are necessary to confirm the existence of non-Mendelian forms of expression and linked QTL affecting multifactorial traits in livestock. Sex $\times$ QTL interactions can be easily analysed with adequate experimental designs. Regarding genomic imprinting, several experimental crosses, such as $\mathrm{F}_{2}$ between outbred lines herein or backcrosses from $F_{1}$ individuals with both paternal and maternal founders, allow detecting potentially imprinted genome regions. Another possibility would be to perform functional studies and look at mRNA expression. The presence of linked QTLs can be confirmed by means of new experiments that allow breaking the linkage between QTLs, for instance by developing advanced intercross lines or interval-specific congenic strains as described by Darvasi [9]. Other strategies, such as the development of metaanalyses of several experiments [33], would also allow gaining some power to study the location and mode of expression of genome regions contributing to genetic variation of multifactorial traits.

\section{ACKNOWLEDGEMENTS}

This experimental program was funded by the European Union (Bridge and Biotech + programs), INRA (Department of Animal Genetics and AIP "structure des génomes animaux") and the "groupement de recherches et d'études sur les génomes”. R.Q. acknowledges the Universidad Pública de Navarra for funding her post-doctoral stage at INRA. 


\section{REFERENCES}

[1] Alfonso L., Haley C.S., Power of different F2 schemes for QTL detection in livestock, Anim. Sci. 66 (1998) 1-8.

[2] Andersson-Eklund L., Marklund L., Lundstrom K., Haley C.S., Andersson K., Hansson I., Moller M., Andersson L. Mapping quantitative trait loci for carcass and meat quality traits in a wild boar $\times$ Large White intercross, Anim. Sci. 76 (1998) 694-700.

[3] Andersson L., Haley C.S., Ellegren H., Knott S.A., Johansson M., Andersson K., Andersson-Eklund L., Edfors-Lilja I., Fredholm M., Hansson I., Hakansson J., Lundström K., Genetic mapping of quantitative trait loci for growth and fatness in pigs, Science 263 (1994) 1771-1774.

[4] Archibald A.L., Brown J.F., Couperwhite S., Mc Queen H.A., Nicholson D., Haley C.S., Coppieters W., Van de Weghe A., Stratil A., Winterš A.K., Fredholm M., Larsen N.J., Nielsen V.H., Milan D., Woloszyn N., Robic A., Dalens M., Riquet J., Gellin J., Caritez J.C., Hue D., Burgaud G., Ollivier L., Bidanel J.P., Vaiman M., Renard C., Geldermann H., Davoli R., Ruyter D., Versteger E.J.M., Groenen M.A.M., Davies W., Hšyheim B., Keiserud A., Andersson L., Ellegren H., Johansson M., Marklund L., Miller J.R., Anderson Dear D.V., Signer E., Jeffreys A.J., Moran C., Le Tissier P., Rothschild M.F., Tuggle C.K., Vaske D., Helm J., Liu H.C., Rahman A., Yu T.P., Larson R.G., Schmitz C.B., The PiGMaP consortium linkage map of the pig (Sus scrofa), Mamm. Genome 6 (1995) 157175.

[5] Bidanel J.P., Milan D., Iannuccelli N., Amigues Y., Boscher M.Y., Bourgeois F., Caritez J.C., Gruand J., Le Roy P., Lagant H., Quintanilla R., Renard C., Gellin J., Ollivier L., Chevalet C., Detection of quantitative trait loci for growth and fatness in pigs, Genet. Sel. Evol. 33 (2001) 289-309.

[6] Blagitko N., Mergenthaler S., Schulz U., Wollmann H.A., Craigen W., Eggermann T., Ropers H.H., Kalscheuer V.M., Human GRB10 is imprinted and expressed from the paternal and maternal allele in a highly tissue- and isoformspecific fashion, Hum. Mol. Genet. 9 (2000) 1587-1595.

[7] Casas-Carrillo E., Prill-Adams A., Price S.G., Clutter A.C., Kirkpatrick B.W., Mapping genomic regions associated with growth rate in pigs, J. Anim. Sci. 75 (1997) 2047-2053.

[8] Churchill G.A., Doerge R.W., Empirical threshold values for quantitative trait mapping, Genetics 138 (1994) 963-971.

[9] Darvasi A., Experimental strategies for the genetic dissection of complex traits in animal models, Nature Genet. 18 (1998) 19-24.

[10] de Koning D.J., Janss L.L.G., Rattink A.P., van Oers P.A.M., de Vries B.J., Groenen M.A.M., van der Poel J.J., de Groot P.N., Brascamp E.W., van Arendonk J.A.M., Detection of quantitative trait loci for backfat thickness and intramuscular fat content in pigs (Sus scrofa), Genetics 152 (1999) 1679-1690.

[11] de Koning D.J., Rattink A.P., Harlizius B., van Arendonk J.A.M., Brascamp E.W., Groenen M.A.M., Genome-wide scan for body composition in pigs reveals important role of imprinting, Proc. Natl. Acad. Sci. USA 97 (2000) 7947-7950. 
[12] Ellegren H., Chowdhary B., Johansson M., Andersson L., A primary linkage map of the porcine genome reveals a low rate of recombination, Genetics 137 (1994) 1089-1100.

[13] Falconer D.S., Mackay T.F.C., Introduction to Quantitative Genetics, Longman, United Kingdom, 1996.

[14] Georges M., Cockett N., The ovine callipyge locus: a paradigm illustrating the importance of non-Mendelian genetics in livestock, Reprod. Nutr. Dev. 36 (1996) 651-657.

[15] Green P., Falls K., Crooks S., Documentation for CRIMAP version 2.4, Washington University School of Medicine, St. Louis (1990).

[16] Haley C.S., Knott S.A., Elsen J.M., Mapping quantitative trait loci in crosses between outbred lines using least squares, Genetics 136 (1994) 1195-1207.

[17] Jeon J.T., Carlborg O., Törnsten A., Giuffra E., Amarger V., Chardon P., Andersson-Eklund L., Andersson K., Hansson I., Lundström K., Andersson L., A paternally expressed QTL affecting skeletal and cardiac muscle mass in pigs maps to the IGF2 locus, Nature Genet. 21 (1999) 157-158.

[18] Knott S.A., Marklund L., Haley C.S., Andersson K., Davies W., Ellegren H., Fredholm M., Hansson I., Hoyhem B., Lundström K., Moller M., Andersson L., Multiple marker mapping of quantitative trait loci in a cross between outbred Wild Boar and Large White pigs, Genet. 149 (1998) 1069-1080.

[19] Lee K., Dekkers J.C.M., Fernando R.L., Rothschild M.F., Evaluation of statistical models and permutation test for detecting gametic imprinting in QTL scans, in: Abstracts of the ASAS/ADSA Joint Annual Meeting, 24-28 July 2001, Indianapolis, USA, pp. 190.

[20] Marklund L., Nyström P.E., Stern S., Andersson-Eklund L., Andersson L., Confirmed quantitative trait loci for fatness and growth on pig chromosome 4, Heredity 82 (1999) 134-141.

[21] Morison I.M., Paton C.J., Cleverley S.D., The imprinted gene and parent-oforigin effect database, Nucleic Acids Res. 29 (2001) 275-276.

[22] Nezer C., Moreau L., Brouwers B., Coppieters W., Detilleux J., Hanset R., Karim L., Kvasz A., Leroy P., Georges M., An imprinted QTL with major effect on muscle mass and fat deposition maps to the IGF2 locus in pigs, Nature Genet. 21 (1999) 155-156.

[23] Ovilo C., Pérez-Enciso M., Barragan C., Clop A., Rodriguez C., Oliver M.A., Toro M.A., Noguera J.L., A QTL for intramuscular fat and backfat thickness is located on porcine chromosome 6, Mamm. Genome 11 (2000) 344-346.

[24] Paszek A.A., Wilkie P.J., Flickinger G.H., Rohrer G.A., Alexander L.J., Beattie C.W., Shook L.B., Interval mapping of growth in divergent swine cross, Mamm. Genome 10 (1999) 117-122.

[25] Pérez-Enciso M., Clop A., Noguera J.L., Ovilo C., Coll C., Folch J.M., Babot D., Estany J., Oliver M.A., Diaz I., Sanchez A., A QTL on pig chromosome 4 affects fatty acid metabolism: evidence from an Iberian by Landrace intercross, J. Anim. Sci. 78 (2000) 2525-2531.

[26] Perez Jurado L.A., Peoples R., Kaplan P., Hamel B.C., Francke U., Molecular definition of the chromosome 7 deletion in Williams syndrome and parent-oforigin effects on growth, Am. J. Hum. Genet. 59 (1996) 781-792. 
[27] Rohrer G.A., Alexander L.J., Keele J.W., Smith T.P.L., Beattie C.W., A microsatellite linkage map of the porcine genome, Genetics 136 (1994) 231-245.

[28] Rohrer G.A., Alexander L.J., Hu Z., Smith T.P.L., Keele J.W., Beattie C.W., A comprehensive map of the porcine genome, Genome Res. 6 (1996) 371-391.

[29] Rohrer G.A., Keele J.W., Identification of quantitative trait loci affecting carcass composition in swine: I. fat deposition traits, J. Anim. Sci. 76 (1998) 2247-2254.

[30] Rohrer G.A., Keele J.W., Identification of quantitative trait loci affecting carcass composition in swine: II. Muscling and wholesale product yield traits, J. Anim. Sci. 76 (1998) 2255-2262.

[31] Rothschild M.F., Liu H.C., Tuggle C.K., Yu T.P., Wang L., Analysis of pig chromosome 7 genetic markers for growth and carcass performance traits, J. Anim. Breed. Genet. 112 (1995) 341-348.

[32] Walling G.A., Archibald A.L., Visscher P.M., Haley C.S., Mapping of quantitative trait loci on chromosome 4 in a Meishan $\times$ Large White Meishan pig F2 population, in: Proceedings of the 6th World Congress on Genetics Applied to Livestock Production, 11-16 January 1998, Vol. 23, University of New England, Armidale NSW 2351, pp. 519-522.

[33] Walling G.A., Visscher P.M., Andersson L., Rothschild M.F., Wang L., Moser G., Groenen M.A.M., Bidanel J.P., Cepica S., Archibald A., Geldermann H., de Koning D.J., Milan D., Haley C.S., Combined analyses of data from QTL mapping studies: chromosome 4 effects on porcine growth and fatness, Genetics 155 (2000) 1369-1378.

[34] Wang L., Yu T.P., Tuggle C.K., Liu H.G., Rothschild M.F., A directed search for quantitative trait loci on chromosomes 4 and 7 in the pig, J. Anim. Sci. 76 (1998) 2560-2567.

[35] Yoshihashi H., Maeyama K., Kosaki R., Ogata T., Tsukahara M., Goto Y., Hata J., Matsuo N., Smith R.J., Kosaki K., Imprinting of human GRB10 and its mutations in two patients with Russell-Silver syndrome, Am. J. Hum. Genet. 67 (2000) 476-482.

[36] Yu T.P., Wang L., Tuggle C.K., Rothschild M.F., Mapping genes for fatness and growth on pig chromosome 13: A search in the region close to the pig PIT1 gene, J. Anim. Breed. Genet. 116 (1999) 281-288.

[37] Zimprich A., Grabowski M., Asmus F., Naumann M., Berg D., Bertram M., Scheidtmann K., Kern P., Winkelmann J., Muller-Myhsok B., Riedel L., Bauer M., Muller T., Castro M., Meitinger T., Strom T.M., Gasser T., Mutations in the gene encoding epsilon-sarcoglycan cause myoclonus-dystonia syndrome, Nat. Genet. 29 (2001) 66-69.

To access this journal online: www.edpsciences.org 